\title{
Assessment of blood donor selection and deferral pattern in a tertiary care hospital in Central India
}

\author{
Kujur P. ${ }^{1}$, Kumar Tiwari A. ${ }^{2 *}$, Bagde S. $^{3}$, Bombeshwar V. ${ }^{4}$, Ranjan Behera T. ${ }^{5}$ \\ DOI: https://doi.org/10.17511/jopm.2020.i01.13
}

\footnotetext{
1 Pratima Kujur, Professor, Department of Pathology, Government Medical College, Rajnandgaon, Chattisgarh, India.

2* Amit Kumar Tiwari, Assistant Professor, Department of Pathology, Government Medical College, Rajnandgaon, Chattisgarh, India.

3 Sadhna Bagde, Associate Professor, Department of Pathology, Government Medical College, Rajnandgaon, Chattisgarh, India.

${ }^{4}$ Vikash Bombeshwar, Demonstrator, Department of Pathology, Government Medical College, Rajnandgaon, Chattisgarh, India.

5 Tapas Ranjan Behera, Resident, Department of Hematology and Medical Oncoloy, Cleveland Clinic, , Ohio, United States of America.
}

Introduction:Safety and efficacy of blood donations depends on selection of suitable donors. Understanding the prevalent reasons of non-suitability of donors can help understanding the donor pool demographics to develop better donor recruitment and screening strategies. Material and Methods: This is across sectional retrospective study conducted in a tertiary care hospital in central India over a period of two years from January 2017 to December 2018. The donor registry from in hospital donation as well as the blood donation camps were analyzed for the pattern of deferral.Results: Total 18,025 people donated blood during the study period. During this period the number of deferrals was 681 . The overall deferral rate was $3.77 \%$. Males constituted the majority of donors $(17586,97.56 \%)$, and expectedly majority of deferrals were in males $(626,3.47 \%)$. The most common reason of temporary deferral in donors was recent alcohol intake is $197(28.93 \%)$ potential donors which was exclusively in the males. The most common reason of permanent deferral was hypertension $(59,8.66 \%)$. The common reason for deferral among deferred females was low hemoglobin $(26,47.27 \%)$ and that in deferred males was alcohol intake $(197,31.46 \%)$. Conclusion: Donor deferral is essential to ensure the safety of both the donor and recipient of the blood; however, it can also lead to non-return of temporarily deferred donors. A pattern and trend in donor deferral could be used as a reference for developing policy and future initiatives in donor education, encouragement and retention.

Keywords: Blood transfusion, Deferral, Donor selection

\section{Corresponding Author}

Amit Kumar Tiwari, Assistant Professor, Department of Pathology, Government Medical College, Rajnandgaon, Chattisgarh, India. Email: dramittiwari01@gmail.com

\section{How to Cite this Article}

Kujur P, Tiwari AK, Bagde S, Bombeshwar V, Behera TR. Assessment of blood donor selection and deferral pattern in a tertiary care hospital in Central India. Trop J Pathol Microbiol. 2020;6(1):83-88. Available From

https://pathology.medresearch.in/index.php/jopm/ar ticle/view/390
To Browse

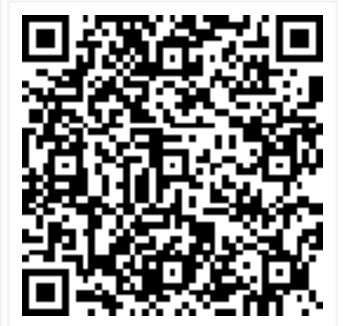

Manuscript Received 10-12-2019

Conflict of Interest No

Review Round 1
20-12-2019
Funding
Nil

Cor () 2020 by Pratima Kujur, Amit Kumar Tiwari, Sadhna Bagde, Vikash Bombeshwar, Tapas Ranjan Behera and Published by
Siddharth Health Research and Social Welfare Society. This is an Open Access article licensed under a Creative Commons Attribution 4.0 International License https://creativecommons.org/licenses/by/4.0/ unported [CC BY 4.0].

\author{
Review Round 2 \\ 27-12-2019 \\ Ethical Approval \\ Yes
}

Accepted 02-01-2019

Note 


\section{Introduction}

Safe blood transfusion is ensured through selection of appropriate donor population, testing of collected blood, post donation treatment of blood, maintenance of donor deferral registry and safe blood transfusion practices. Donation of blood may be voluntary non-remunerated or replacement donation which is required by a member of their own family or community. Although a donation could be voluntary, still many voluntary donors are deferred due to reasons of donor's and to ensure a safe and efficient blood transfusion to the recipient.

Safe donors are encouraged to donate at intervals while the at-risk donors are encouraged to self-defer from donation. The deferral may be temporal postponement or a permanent exclusion from donating blood in future due to existing hematological disease, permanent infective state, or medical condition that could affect the safety of the blood or affect donor's own health. The temporarily deferred population is encouraged to donate once the deferral period is over. Safe and adequate supply of blood and blood products is a public health priority.

According to national AIDS control organization's statistics, the annual rate of blood donation is about 7.4 million units against the requirement of 10 million units in India [1,2] Increasing awareness among people regarding blood transfusion has increased the number of voluntary donors over time. A voluntary donor is one who donates without any rewards or compulsion [3], whereas a replacement donor is one who donates blood upon request of specific patient or patient's family which intended to be used specifically for treatment of a patient [4].

The donors are screened through a mini-physical examination and a health history questionnaire. The standard guidelines are followed to screen common indicators of deferral. Other than being known career of diseases, many healthy individuals are not suitable to donate blood due to various reasons. The ineligible blood donors are considered as deferred donors. The deferral could be temporary or permanent. A temporary deferred donor is deferred for a specific time period.The reasons for deferral have varying prevalence in different regions. Knowledge of the relative prevalence of different causes of deferral in a population would make the donor selection process more focused and effective
Of bloods were donated by developing nations, but these nations have $82 \%$ of world population[5].

Blood demand increases day by day, however changing of socio-economic environment, donor retention and recruitment is a challenge [6], thus study of profile of blood donors could provide insight for increasing pool of safe voluntary blood donors. To achieve this, donor deferral criteria is needed [7] along with stringent screening after donation for transfusion transmitted infection [8]. Variation of causes of deferral from region to region calls for root cause finding and employing measures to enhance awareness among the donor population.

\section{Material and Methods}

Setting: This study carried out in blood bank of Government Medical College, Rajnandgaon, Chhattisgarh, which is a tertiary care hospital in central India.

Duration and type of study: This is a is a retrospective cross-sectional study analyzing the potential donors presenting themselves at the blood bank or blood donation camps between January 2017 to December 2018 and deferred due to temporary or permanent donor deferral criteria.

Sampling methods: National guidelines based standard operating procedure were employed for donor selection and deferral. All the donors were screened for hemoglobin using copper sulphate and blood pressure were noted down for categorization. Questionnaires were asked and documentation of the responses were made.

Inclusion criteria: All donors who presented themselves at the blood bank or any of the blood donation camps were registered through the registry. The deferral cases were included in the study along with the total donation data for relative comparison.

Exclusion criteria: Participants who decided not to proceed with the assessment for qualifying to donate blood before being administered with the questionnaire were excluded from the study.

Data collection procedure: Data was collected from the maintained records in the blood bank from the in house donor screening and blood donation camp data entry records.

Data analysis: Data was analyzed using Microsoft excel. 
Ethical consideration: The ethical approval for the study was obtained from the institutional ethical committee. The information obtained was used for research purpose only.

\section{Results}

Total 18,025 people donated blood during study period, of which 17,586 were male, 439 were females. A total of 681 donors were deferred based on medical history and physical examination including hemoglobin, blood pressure, pulse rate and temperature.

Out of total 681 deferred donors 626 were males and 55 were females. Percentages of deferral of total registration were $3.47 \%$ for males and $0.30 \%$ for females. Demographic profile of blood donors is shown in Table 1.

Table-1: Demographic profile of deferred donors.

\begin{tabular}{|l|l|l|}
\hline & \multicolumn{1}{|c|}{$\begin{array}{c}\text { Number of } \\
\text { Deferred Donors }\end{array}$} & \multicolumn{1}{|c|}{$\begin{array}{c}\text { Deferred Donors as a \% of Total } \\
\text { Eligible Donors (18025) }\end{array}$} \\
\hline Male & 626 & $3.47 \%$ \\
\hline Female & 55 & $0.30 \%$ \\
\hline Total & 681 & $3.77 \%$ \\
\hline
\end{tabular}

In the present study, $84.17 \%$ were replacement donors and $15.83 \%$ were voluntary donors as shown in Table 2.

Table-2: Donor distribution based on type of donation.

\begin{tabular}{|l|l|l|}
\hline & \multicolumn{1}{|c|}{ Number of Donors } & \multicolumn{1}{c|}{$\%$ of Total Donors } \\
\hline Replacement & 15171 & 84.17 \\
\hline Voluntary & 2854 & 15.83 \\
\hline
\end{tabular}

As per records, the reasons of deferral are many as listed. The reasons of deferral were classified as either permanent or temporary deferral. There were $614(90.16 \%)$ temporary deferrals and 67 (9.84\%) permanent deferrals among a total of 681 deferred donors as shown in Table 3.

Table 3: Distribution of temporary and permanent deferrals.

\begin{tabular}{|l|l|l|}
\hline & Number of Deferrals & $\%$ of Total Deferrals \\
\hline Temporary Deferral & 614 & 90.16 \\
\hline Permanent Deferral & 67 & 9.84 \\
\hline Total & 681 & 100 \\
\hline
\end{tabular}

The most common cause of temporary deferral in donors were alcohol 197 (28.93\%), low hemoglobin 103 (15.12\%), low blood pressure 54 (7.93\%), medication $45(6.60 \%)$, Typhoid $44(6.46 \%)$, recent
Donation $41(6.02 \%)$, and low weight 34 (4.99\%) respectively as shown in Table 4 .

Table-4: Reasons of temporary deferral and their proportions.

\begin{tabular}{|c|c|c|c|c|c|}
\hline & Male & Female & Total & $\begin{array}{c}\% \text { Temporary } \\
\text { Deferral }\end{array}$ & $\begin{array}{c}\% \text { of Total } \\
\text { Deferral }\end{array}$ \\
\hline Alcohol & 197 & & 197 & 32.08 & 28.93 \\
\hline Low Hemoglobin & 77 & 26 & 103 & 16.7 & 15.12 \\
\hline $\begin{array}{l}\text { Low Blood } \\
\text { Pressure }\end{array}$ & 51 & 3 & 54 & 8.79 & 7.93 \\
\hline Medication & 40 & 5 & 45 & 7.32 & 6.60 \\
\hline Typhoid & 43 & 1 & 44 & 7.16 & 6.46 \\
\hline Recent Donor & 41 & & 41 & 6.67 & 6.02 \\
\hline $\begin{array}{l}\text { Low Body } \\
\text { Weight }\end{array}$ & 29 & 5 & 34 & 5.53 & 4.99 \\
\hline Recent Surgery & 14 & & 14 & 2.28 & 2.06 \\
\hline Menstruation & & 14 & 14 & 2.28 & 2.06 \\
\hline Fever & 10 & & 10 & 1.6 & 1.47 \\
\hline $\begin{array}{l}\text { High Risk } \\
\text { Behavior }\end{array}$ & 9 & & 9 & 1.46 & 1.32 \\
\hline Malaria & 9 & & 9 & 1.46 & 1.32 \\
\hline Skin Lesion & 9 & & 9 & 1.46 & 1.32 \\
\hline Recent Vaccine & 8 & & 8 & 1.30 & 1.17 \\
\hline Tattoo & 7 & & 7 & 1.14 & 1.03 \\
\hline Underage & 5 & & 5 & 0.81 & 0.73 \\
\hline Tuberculosis & 3 & & 3 & 0.49 & 0.44 \\
\hline $\begin{array}{l}\text { Not Slept in } \\
\text { Night }\end{array}$ & 3 & & 3 & 0.48 & 0.44 \\
\hline Allergy & 2 & & 2 & 0.32 & 0.30 \\
\hline Jaundice & 2 & & 2 & 0.32 & 0.30 \\
\hline $\begin{array}{l}\text { History of } \\
\text { Transfusion }\end{array}$ & 1 & & 1 & 0.16 & 0.15 \\
\hline Total & 560 & 54 & 614 & & \\
\hline
\end{tabular}

Table-5: Reasons of permanent deferral and their proportions.

\begin{tabular}{|l|l|l|l|l|l|}
\hline & Male & Female & Total & $\begin{array}{c}\% \text { Permanent } \\
\text { deferral }\end{array}$ & $\begin{array}{c}\% \text { of Total } \\
\text { deferral }\end{array}$ \\
\hline Hypertension & 58 & 1 & 59 & 88.05 & 8.66 \\
\hline $\begin{array}{l}\text { Uncontrolled } \\
\text { Diabetes }\end{array}$ & 3 & & 3 & 5.08 & 0.45 \\
\hline HIV Positive & 1 & & 1 & 1.69 & 0.15 \\
\hline HBsAg Positive & 1 & & 1 & 1.69 & 0.15 \\
\hline HCV Positive & & & & & \\
\hline VDRL Positive & 1 & & 1 & 1.69 & 0.15 \\
\hline Epilepsy & 1 & & 1 & 1.69 & 0.15 \\
\hline Polio & 1 & & 1 & 1.69 & 0.15 \\
\hline Total & 66 & 1 & 67 & & \\
\hline
\end{tabular}

Among the 67 permanently deferred cases the most common reason was hypertension 59(88.05\%) followed by uncontrolled diabetes $3(5.08 \%)$, HIV 
$1(1.69 \%)$, hepatitis $1(1.69 \%)$, syphilis $1(1.69 \%)$, epilepsy $1(1.69 \%)$, and polio $1(1.69 \%)$ respectively as shown in Table 5.

In males, the most common cause of temporary deferral was alcohol intake (197) followed by low hemoglobin (77), hypertension (58), low blood pressure (51), Typhoid (43), recent blood donation (41) and medication (40) in decreasing order. Whereas in females, the most common cause of temporary deferral was due to low hemoglobin (26), followed by ongoing menstruation (14), medication/low weight (5), low blood pressure (3) and Typhoid (1) in decreasing order as shown in Table 6.

Table 6: Leading causes of deferrals in male and female.

\begin{tabular}{|l|l|}
\multicolumn{1}{|c|}{$\begin{array}{c}\text { Causes of Deferred in } \\
\text { Male(Number) }\end{array}$} & \multicolumn{1}{|c|}{$\begin{array}{c}\text { Causes of Deferred in } \\
\text { Female(Number) }\end{array}$} \\
\hline Alcohol (197) & Low Hemoglobin (26) \\
\hline Low Hemoglobin (77) & Menstruation(14) \\
\hline Hypertension(58) & Medication/Low Weight(5) \\
\hline Low Blood Pressure (51) & Low Blood Pressure (3) \\
\hline Typhoid(43) & Hypertension/Typhoid(1) \\
\hline Recent Blood Donation(41) & \\
\hline Medication Intake (40) & \\
\hline Uncontrolled Diabetes(3) & \\
\hline HBsAg(1) & \\
\hline HIV(1) & \\
\hline
\end{tabular}

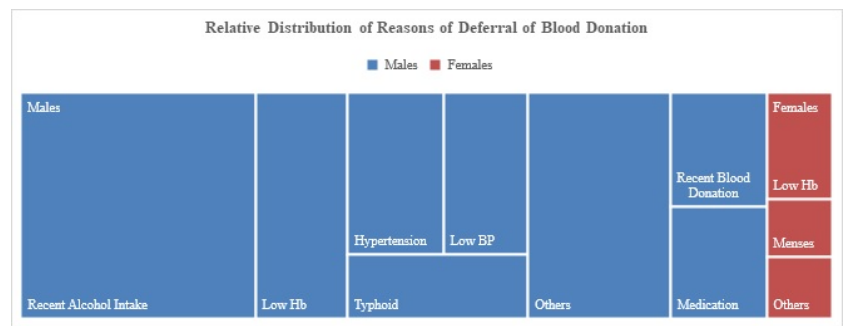

Fig-1. Relative Distribution of Reasons of Deferral in Males and Females

The major cause of deferral exclusive to males in this population was alcohol intake and hypertension. The common major cause of deferral among males and females was low hemoglobin as depicted in Figure 1.

\section{Discussion}

This study attempts to analyze the pattern of blood donation deferral in the tertiary care hospital between 1st January 2017 to 31st December 2018. Donor deferral is painful experience for blood bank [9]. This also leaves the person with negative
Feeling about self as well as blood banking system.

But there are definite advantages of eliminating donors with possible risk of disease because despite the availability of sensitive screening test to detect HIV infection, blood donors can be infected but test negative if they have been infected for a period of 6 weeks or less [10].

In this study it was noted that majority of donor population were from educated youth which could be due to the general better state of health and awareness. In the study conducted by Shashahani et al, it was found that moral duties, altruism, charity, maintenance of one's own health and free blood investigations were some of the factors motivating people to donate blood [10].

The rate of deferral differs from region to region and sometimes in same region between one center to another center [11]. The analysis of the donor deferral pattern in specific demographic areas is important to develop a safe pool of blood donors.

In the present study a total of 18,025 people donated blood, of which $17,586(97.56 \%)$ were male and $439(2.44 \%)$ were females. During this study period $681(3.77 \%)$ donors were deferred.

As noticed in the present study the female donor population-3.77\% was very low as many other studies in Indian subcontinent like -John et al4.92\% [2], Krishna et al.-1.55\%[9], Sunder P et al.-11.27\% [10], Sareen R et al.-8.39\% [12], Chaudhary et al-8.68\% [13], Girish et al.-2.66\% [14], Agarwal et al.-8.39\% [15], Rathod et al.-5.98\% [16].

This may be due to lack of awareness, fear, misconception about physiological reasons, or lack of motivation.

Percentage of temporary deferral due to low hemoglobin in present study was $16.70 \%$, which was near about finding of John et al-15.66\% [2], Chaudhary et al-18.60\% [13], Girish et al.-19.45\% [14], but finding was higher among studies likeKrishna et al.-30.18\% [9], Sunder P et al.-36.48\% [10], Sareen R et al.-39.42\% [12], Agarwal et al.-56.92\% [15], Rathod et al.-42.02\% [16].

Percentage of permanent deferral due to hypertension in present study was $88.05 \%$, which was close to Agarwal et al.-82.60\% [15], Rajendra $\mathrm{N}$ et al.-83.63\% [16], while finding differs in other studies like- John et al-30.30\%[2], Krishna et al.-37.50\% [9], Sareen R et al.-10.73\% [12] and 
Girish et al.-39.95\% [14]. In present study, replacement donation $(15171,84.17 \%)$ was major part of donation, this may be because lack of awareness, fear in donors, while voluntary donation was $(2854,15.83 \%)$ less in number.

The majority of the donors $(614,90.16 \%)$ were deferred due to temporary reasons, and very small group of donors $(67,9.84 \%)$ were deferred permanently.

Overall leading cause of temporary deferral in donors were alcohol $197 \quad(28.93 \%$ exclusively constituted by male donors) and low hemoglobin $103(15.12 \%)$ respectively.

The cause common in both the genders was low hemoglobin, this shows a poor nutritional status among people in the region.Thus, combining anemia prevention and treatment to donor recruitment efforts could help regain the donors and develop a healthy blood donor pool.

Among permanent deferrals, hypertension is the most common cause $(88.05 \%)$. However, it is third most common cause of total deferral $(8.66 \%)$, in most of the deferred donors it was an incidental finding during pre-donation screening, which could be due to fear of phlebotomy or stress.

Limitation of the study: The present study acknowledged the weakness of the study being an analysis of data from two years. Adding more extensive information could have yielded more useful data. The center being a tertiary care center, it caters to the accessible areas surrounding it while it fails to capture the demographics of the surrounding tribal area population which get the treatment from the local primary care hospital due to lack of easy transport to the city.

\section{Conclusion}

Most of donors deferred due to temporary reasons $(90.16 \%)$. Main cause of temporary deferral in present study can be overcome by alcohol abstinence. To avoid temporary reasons for deferral and increase pool of donors, awareness and continuous education regarding cause as well as time period of deferral is very important. It can be done by advertising campaign and distribution brochure providing information of blood products, deferral criteria and clarification of myth about blood donation. The donors should be motivated for further visit to the camp and blood bank.

\section{What the study adds to existing knowledge?}

This study describes the loco regional aspect of central India which has not been published in other similar studies. Since the donor retention strategies and public awareness program depend on the issues prevalent in the local population, this study will help policy makers device appropriate policy to encourage local population participate in voluntary blood donation.

\section{Author's contributions}

Dr Pratima Kujur: Data analysis

Dr. Amit Kumar Tiwari: Data collection, manuscript writing

Dr. Sadhna Bagde: Study concept and data analysis

Dr. Vikash Bombeshwar: Study concept and manuscript writing

Dr. Tapas Ranjan Behera: Data collection, manuscript writing

\section{Reference}

01. Government of Karnataka. Annual Action Plan. Karnataka State AIDS Prevention Society. 20112012; p-129.

Available

[Article:https://ksaps.gov.in/pdfs/annual_actionplan2 011_12.pdf][Crossref]

02. John F, Varkey MR. Evaluation of blood donor deferral causes in a tertiary hospital, South India. Int J Biomed Adv Res. 2015;6(3)253-258. doi: [Article:https://doi.org/10.7439/ijbar.v6i3.1833] [Crossref]

03. WHO. Biregional Workshop on Blood Donor Management. WHO. Meeting Report p-8.

Available

[Article:http://iris.wpro.who.int/handle/10665.1/106

28][Crossref]

04. WHO. Technical Report Series No 941,2007; Recommendation for the production, control and regulation of human plasma for fractionation. WHO. p-195.

Available from TRS941Annex4blood.pdf [Article:https://www.who.int/bloodproducts/publicatio ns/][Crossref] 
04. Shenga N, Pal R, Sengupta S. Behaviour disparities towards blood donation in Sikkim, India. Asian J Transfusion Sc. 2008;2(2)56-60.

doi: [Article:https://dx.doi.org/10.4103\%2F09736247.42692][Crossref]

05. Baxi A. Misconceptions over blood donation causing shortage in India. Sunday Economic Times. [online] February 10,2008.

Available

from

[Article:https://economictimes.indiatimes.com/consu mer-life/misconceptions-over-blood-donation-

causing-shortage-in-india/articleshow/2770144.cms] [Crossref]

06. Newman B. Blood donor suitability and allogenic whole blood donation. Transfus Med. 2001;15(3)234-244.

doi:

[Article:https://doi.org/10.1053/tmrv.2001.24593]

[Crossref]

07. Rajendra N, Madapura VP. Study of blood donor profile in a blood bank attached to a medical college hospital - a retrospective study. JOPM. 2017;3(4)406-411.

Available

from:

[Article:https://pathology.medresearch.in/index.php/j opm/article/view/110][Crossref]

08. Choudhary LP, Tetali S. Notification of transfusion transmitted infection. Indian J Med Ethics. 2008;5(2)58-60.

doi:[Article:https://doi.org/10.20529/IJME.2008.022] [Crossref]

09. Talonu T. Causes of volunteer blood donor rejection in Papua New Guinea. P N G Med J. 1983;26(3-4)195-197.

[Crossref]
09. rishna MC, Sharada MS, Harish SG, Hulinaykar RM. An analysis of pre-donation deferral of blood donors in a tertiary care teaching hospital blood bank unit, Tumakur, Karnataka, India. Int J Healthcare Sci. 2015;2(2)258-262.

[Crossref]

10. Sunder $P$, Sangeetha $S K$, Seema DM, Marimuthu $P$, Shivana N. Pre-donation deferral of blood donors in Suth Indian set-up- An analysis. Asian J Transfus Sci. 2010;4(2)112-115.

doi: [Article:https://dx.doi.org/10.4103\%2F09736247.67037][Crossref]

11. Agrawal PB, Goswami D, Surana SS, Shashi S. Pre-donation deferral of blood donors in tertiary care hospital attached to medical college in Southern Rajasthan. J Pharm Biomed Sci. 2016;6(7)460-463.

[Crossref]

12. Sareen R, Gupta GN, Dutt A. Donor awarenesskey to successful voluntary blood donation. Asian J Transfus Sci. 2012;1;29.

doi:

[Article:https://doi.org/10.12688/f1000research.129.v1][Crossref]

13. Choudhary RK, Gupta D, Gupta RK. Analysis of donor deferral pattern in a voluntary blood donor population. Transfus Med. 1995;5(3)209212.

doi: [Article:https://doi.org/10.1111/j.13653148.1995.tb00230.x][Crossref]

14. Girish CJ, Chandrashekhar TN, Ramesh BK, Kantikar SM. Pre-donation deferral of whole blood donors in district transfusion centre. J Clin Diagnos Res. 2012;6(1)47-50.

[Crossref] 